\title{
How to Protect the Human Rights of Children Temporarily out of Custody in the Novel Coronavirus Pneumonia Epidemic in China
}

\author{
Xinlin Peng ${ }^{1}$, Qian Sun ${ }^{2, *}$ \\ ${ }^{1}$ Law School, Beijing Normal University, Beijing, China \\ ${ }^{2}$ Faculty of Humanities and Social Sciences, Beijing Institute of Education, Beijing, China \\ Email address: \\ xinlin@bnu.edu.cn (Xinlin Peng), 398942351@qq.com (Qian Sun) \\ ${ }^{*}$ Corresponding author
}

To cite this article:

Xinlin Peng, Qian Sun. How to Protect the Human Rights of Children Temporarily out of Custody in the Novel Coronavirus Pneumonia Epidemic in China. International Journal of Law and Society. Vol. 3, No. 1, 2020, pp. 5-11. doi: 10.11648/j.ijls.20200301.12

Received: February 25, 2020; Accepted: March 10, 2020; Published: March 24, 2020

\begin{abstract}
In the current epidemic prevention and control of the Novel Coronavirus Pneumonia (NCP) in China, the protection of human rights of children temporarily separated from guardianship during the epidemic period has not yet attracted the attention of the state and society. Some of these children have to be separated from their parents because their parents are quarantined for suspected or confirmed NCP, or these children themselves have to be quarantined because of suspected or confirmed diagnosis of NCP. Some children's parents are doctors, police and other front-line anti epidemic staff, therefore they have no other choice but leaving the children at home alone. There are also children whose parents and other close relatives have been infected or suspected to be infected with NCP thereby have no ability to take care of them. These children are actually out of the custody of their parents. The mental and physical health of these children are suffering from great damage. However, the absence of state guardianship, guardians' lacking awareness of protecting children's rights, and the adverse guidance of public opinions make these children be in a struggling situation at present. The First thing we must to do is establishing a systematic national guardianship system, and make clear the temporary guardianship system. Second, expanding the interpretation of leftover children and children in difficulties in the existing laws and policies, and formulating special provisions for the protection of temporary "leftover children" during the epidemic prevention and control period should be added. Third, for the "leftover children" who are temporarily out of custody in epidemic areas, the state needs to allocate special to designate special national treatment institutions where children can receive unified treatment.
\end{abstract}

Keywords: "Leftover Children" out of Custody, Novel Coronavirus Pneumonia, National Guardianship, Temporary Guardianship

\section{Introduction}

Since the outbreak of Novel Coronavirus Pneumatia (NCP) in late January, 2020, China has been fighting the epidemic with all its strength. After the closure of Wuhan City on January 23, all provinces of China have taken isolation measures to persons had physical contacts with people who ever stayed in Hubei Province from December 2019 to January 2020. All communities and villages around the country have taken various actions to restrict the movement of people and investigate suspected cases. However, in the context of such a large-scale anti epidemic campaign, we have ignored the protection of human rights of a special group, that is, children, especially those who are temporarily out of custody. These children are called special "leftover children". In this social crisis, children are the members among the society who have the weakest right to speak, but suffer the most. Their needs are often ignored by society and the state.

\section{The Situation of "Leftover Children" out of Custody During the Epidemic}

During the outbreak of the epidemic, several cases showing 
that children are temporarily out of custody are exposed on the Internet. Those cases are distressing and worrying.

Case 1: on January 29, 2020, an article entitled "family suspected NCP was isolated, a Hubei 17-year-old child with cerebral palsy died after staying alone at home for 6 days " introduced Yan Xiaowen, a villager from Yanjia village, Huajiahe Town, Hongan County, Huanggang City, Hubei Province, who was isolated due to suspected NCP. His 17-year-old son with cerebral palsy was alone at home for 6 days and died on January 29. On January 17, Yan Xiaowen, a single father working in Wuhan, returned to Yanjia village with his two sons. Three days later, Yan Xiaowen had fever symptoms. Suspected of being infected by NCP, Yan Xiaowen and his little son were sent to the centralized treatment site in Hong'an county. Because Yan Cheng did not have the ability to act independently, and did not have the symptoms of NCP, what's more, the hospital bed was tense, he was left at home alone. According to the village committee, Yan Cheng, a 17-year-old child with cerebral palsy, ate food on the 24th and 26th and was fed two cups of amino acids by a village doctor on the 28th. Because Yan Xiaowen was confirmed to be infected with NCP on 29th, Yan Cheng, as a close contact, was more likely to be infected. At about $11 \mathrm{am}$ on 29th, the township hospital transferred Yan Cheng to the central observation point of Huajiahe town for isolation treatment. At 12:30, Yan Cheng died. The cause of death remains to be determined. In response, the government of Hong'an county formed a joint investigation team on January 30th. On January 31st, the government of Hong'an County claimed that the Party committee and the government of Huajiahe town had some problems during the period of epidemic prevention and control, such as inaccurate work style, inadequate implementation of the responsibility for epidemic prevention and control, and made a decision to exempt Wang Baoquan, Secretary of the Party committee of Huajiahe Town, and Peng Zhihong, mayor of the town. The County Commission for Discipline Inspection and Aupervision filed a case aiming at Wang Baoquan and Peng Zhihong. [1]

Case 2: according to beiqing.com on February 7, Fuyang, Anhui Province, a couple was quarantined for suspected NCP and their 8-month-old baby was left without caring. Yang Hongxing, a male nurse at Fuyang No. 2 people's Hospital, volunteered to be a temporary father and took turns taking care of the baby with his colleagues. According to Yang Hongxing, they take three shifts to take care of the baby in turn for 3 days. Later, the child was transferred to Pediatrics for treatment as it tested negative for NCP, and the parents tested negative. They all discharged now. [2]

Case 3: according to Kankanews.com, Ms Duan and her husband from Yuncheng, Shanxi Province, worked in Zhejiang Province. Before the Spring Festival, they returned to their hometown, Yuncheng, Shanxi Province, where they were quarantined for suspected NCP infection, leaving their 8 -year-old son at home alone. During the isolation period, Ms. Duan left her mobile phone to her son for convenient contact. The boy downloaded the game with his mother's mobile phone, swiped several credit cards of his parents, and spent 1,3000 yuan to play mobile games. [3]

Case 4: according to Yinchuan wenming.com, at 11:00 p.m. on February 1, Yinchuan Maternal and Child Healthcare hospital $(\mathrm{MCH})$ received a special task assigned by the municipal government to temporarily receive three children for isolation observation and living care. Because the children's parents have been diagnosed with NCP. Three children, the oldest is 6 years old, the second is 4 years old, and the youngest is a baby just born for 45 days. $\mathrm{MCH}$ immediately coordinated three relatively safe isolation single wards to observe, take care of and isolate the three children. At the same time, four nurses were transferred from the Department of Neonatology, Pediatrics, Surgery and Rehabilitation Coordination to take care of three children in shifts. MCH said that in addition to being responsible for children's physical health, children's mental state should not be ignored. The four nurses not only take care of children's daily life, but also are responsible for children's psychological counseling. [4]

Case 5: According to the People's Daily news on February 5, Niu Niu, a son of Mr. Zhang, a doctor of Wuhan hospital, and his mother went abroad for tourism before the Spring Festival. On January 28, after their flight landed in Shanghai, they were arranged to be separated and observed in a hotel. On February 3 , the boy's mother was tested positive for NCP and sent to the hospital for isolation treatment. At that time, Mr. Zhang was fighting in the front line of anti epidemic in Wuhan hospital. The 9-year-old boy was isolated in the hotel alone and left unattended. According to the person in charge of the isolation point appointed by Pudong district health care, the centralized isolation hotel has three meals a day and a special person to deliver meals to the boy. Every day, there are people in the hotel to look after the boy at a fixed time. The Pudong New Area Bureau of Culture, Sports and Tourism send a special personnel to take care of the boy's mental health, daily life, and ensure the nutrition supply. At the same time, the "love hotline" connecting "Pudong New Area Culture and Sports Tourism Bureau - isolation point - Wuhan hospital" was opened immediately. Mr. Zhang can contact Shanghai through the hotline to master and exchange the boy's living conditions timely. [5]

Case 6: According to China News Service on February 4, $\mathrm{Mr}$. Wu, a police officer at the terminal of the Airport Public Security Bureau of Henan Provincial Public Security Bureau, and his wife, who worked in the Henan general hospital of Armed Police, first put themselves into the prevention and control of the epidemic after receiving the task of fighting against the epidemic, leaving their 7-year-old son at home alone. The child lived by eating instant noodles every day. [6]

Case 7: a 6-year-old girl in Hongshan District, Wuhan, Hubei Province was isolated in the home by herself. Her father was isolated in the isolation point due to suspected infection of $\mathrm{NCP}$, while her mother was also isolated at home due to fever, vomiting and other symptoms. Her mother suspected that she was also infected NCP so she could not take care of the girl. In this case, she asked for help, hoping kind-hearted persons 
could provide her daughter with meals every day. The girl cried and made trouble in the room alone, with separation anxiety disorder. [7]

Besides the above cases, many similar cases can be found on the Internet. The above seven cases are selected in this paper mainly based on the type of institutions that voluntarily take care of the children. In the first case, the village committee where the children lived take the responsibility to take care of the child. In the second case, it is the hospital which received suspected NCP patients voluntarily took care of the children. Children in the third and the sixth cases are all unattended. $\mathrm{MCH}$ in the fourth case is designated by the municipal government to be exclusively responsible for the children's maternal and health care. The fifth case is the isolation and the tourism bureau send people to take care of the child. Among them, in the fourth case, government designated the institution to look after children, and the $\mathrm{MCH}$ itself has the qualification and ability to take care of children, which can take into account the physical and mental health of children. Several other cases were organized by non-governmental organizations without the participation of the government. However, the third and sixth cases showed the status quo of children's survival without care. In the first case, although the child is in the care of the village committee, it is entrusted by his father. The village committee did not take the initiative to take responsibility, and children with cerebral palsy belong to special children, requiring 24-hour care by professionals. Obviously, the village committee did not fulfill their responsibilities, and when they realized that they could not take care of the child, they did not recognize the seriousness of the problem, take the initiative to report the case to higher authorities, and ask the government to assign professional carers to take care of the child. After the death of child, the village committee shirked responsibility. During this period, the father of the child turned to the Disabled Persons' Federation for help, but did not get help. The NCP isolation point where the child's father is located did not admit the child with quadriplegic cerebral palsy as the child does not have the ability of autonomous movement, and beds in the isolation point are limited. Therefore, not only the village committee shirked the responsibility after the accident, but the civil affairs department also try to clarify that they are not responsible to this case. Finally, the higher authority of the isolation point, Huajiahe town government, took the responsibility. The seventh case represents a common situation that parents, grandparents and other close relatives of children have been infected or suspected to be infected with NCP in Hubei Province. Because of the tension of hospital limited beds, some patients can't be admitted and can only be isolated at home. Although in such family, children are accompanied by guardians, in fact, guardians have no ability to take care of children.

Generally speaking, these "leftover children" during epidemic outbreaks are classified into three categories. The first category is that the parents are isolated due to suspected or confirmed NCP, and the children are separated from their parents' custody; or the children are also suspected or confirmed NCP, and have to be isolated. The second category is that the parents are doctors, police and other front-line anti epidemic staff, leaving the children at home alone. There are also situations that parents and other relatives have been infected with NCP or are suspected of being infected with NCP therefore lose the ability to take care of their children, which means that these children are actually separated from their parents' custody.

Concerning the current social situation, the hospitals that treat NCP patients take part of the responsibility of caring for the first category of "leftover children". However, because the hospitals need to treat NCP patients, they are already in overload operation. The care of such "leftover children" is only a drop in the bucket, and they can only care for some children for a short time, but cannot cover all such "leftover children". While the school where the children are located take part of responsibility to look after the second type of "leftover children", most schools monitored theses children through online video. Social workers, caring people or neighbors entrusted by their parents may be able to help to provide those children's daily meals, but in fact, such children are still in a state of separation out of custody. The third category of children is currently the most at risk category of children who are still unattended.

\section{The Damage of Epidemic to the Basic Rights of "Leftover Children"}

Children, especially those infants and young children, are the most vulnerable group in social crisis events. They are not able to protect themselves, or have strong willpower to deal with all kinds of misfortunes in social crisis events. Therefore, once these children are not cared well, they will suffer various physical and mental injuries, even death and injury events, and these injuries may become their lifelong psychological shadow. These special "leftover children" need more social attention and national attention. The sudden death of the 17-year-old son with cerebral palsy and quadriplegia, in Huanggang, Hubei Province had made a wake-up call. We hope it is an extreme case. At present, the most worrying thing is physical health damage and psychological trauma caused by the epidemic isolation to children.

Epidemic isolation would damage mental health of "leftover children". For the isolated treatment of NCP patients, as an adult, he is able to accept it. However, for children, especially young children, no matter whether they are infected with NCP or not, once isolated, they will cause psychological trauma. First of all, children's intelligence level can not understand such social crisis events, and in the face of danger, children's parents are the spiritual pillar of children and an important source of children's sense of security. So in this kind of social crisis event, they are forced to be separated from their parents and isolated separately, which makes these children do extreme reactions. They may be in panic for a long time, full of fear, afraid of the dark, crying, screaming, and even do not eat or drink for a long time, do not communicate with others, 
or indulge in online games, do not eat, drink or sleep. All of these actions are the manifestations of children's psychological trauma. At the same time, because of the high infectivity of the NCP and various terrorist rumors in the society, this kind of "leftover children" has also become the object of people's implicit discrimination. Because they are either close contacts of the infected or themselves are suspected infected, people tend to stay away from this kind of children and avoid contact with this kind of children, therefore, this kind of children are indirectly isolated from the outside world. This kind of implicit discrimination will also lay an eternal wound children's psychology, making them hate outsiders or close themselves for a long time and refuse to communicate with outsiders. These psychological traumas are not limited to children who are suspected or diagnosed with NCP, the above-mentioned children whose parents are doctors, nurses and police, who have to fight in the front line of anti epidemic daily, are forced to stay at home alone, they will suffer psychological traumas and implicit discrimination as well, because their parents are all directly exposed to the source of NCP infection.

Epidemic isolation would damage the physical health of "leftover children". Isolation not only causes mental trauma to the separated children, but also seriously damages their health. For example, in the above-mentioned case 6, 7-year-old children can only eat instant noodles at home every day. Eating instant noodles for a long time not only cause malnutrition, but cause many gastrointestinal diseases as well. In the third case mentioned above, the 8-year-old boy was isolated at home alone and addicted to mobile games. In addition to causing direct economic losses to their parents, his physical health damaged directly. In the face of social crisis, no matter how parents teach children to be strong, children who are separated from their parents and isolated at home alone and in fear do have problems with daily diet. Even if three meals can be provided by outsiders, they will not be able to get enough nutrition. And the misuse of home appliances, or other accidents, may cause children's death and injuries. In case 7 above, although the children have close relatives at home, they can't be taken care of, because the children's close relatives themselves have been infected or suspected to be infected with the virus. Those infected or suspected to be infected adults may infect the children at any time, and the children themselves are also suspected cases. If these children can't be admitted to hospital in time, they are likely to die.

The United Nations Convention on the Rights of the Child stipulates four basic rights enjoyed by children, which is the right to survival, the right to development, the right to protection and the right to participation. These four basic rights are also confirmed by the Law of the People's Republic of China on the Protection of Minors. Among them, the right to exist refers to the inherent right of life and health enjoyed by every child. The right to development refers to the right of children to fully develop their physical and intellectual abilities. The right to be protected refers to the right of children not to be adversely affected by their own development and to be protected. The state should take all appropriate measures to ensure that children are protected. The right to participate refers to the right of children to participate in the family, cultural and social life. But in the face of the epidemic, for those "leftover children", they can not even get the basic right to survival, not to mention the right to development, participation and protection.

\section{Social Problems Exposed in the Protection of Children's Rights During the Epidemic}

The United Nations Convention on the Rights of the Child establishes the principle of the best interests of the child. China's civil law, criminal law, marriage and family related laws, as well as education laws, all recognize that children should be given special priority protection. When recognizing the four basic rights of children, the Convention on the rights of the child also proposes that the state should take all appropriate measures to ensure the protection of children. Article 19 of the Law of the People's Republic of China on the Prevention of Juvenile Delinquency stipulates that parents or other guardians of minors shall not allow minors under the age of 16 to live separately from their guardianship. Though in the difficult period of epidemic, we shall not forget the children who need to be cared for and leave them in the situation of being unattended.

\subsection{Absence of National Guardianship}

According to the cases of children's separation from guardianship revealed on the Internet, although some organizations or personnel temporarily act as guardians to provide children necessities in daily life, these temporary guardians show the characteristics of individual case, arbitrariness, unprofessional and regional. The so-called characteristics of individual case refers to the case that the hospital nurses spontaneously form "temporary mothers", which is only limited to a small number of "leftover children" to be cared for, only one or two cases. If the number is too large, as the hospital itself is in the front line of anti epidemic, and has been overloaded, it is impossible to draw out healthcare personnel to care for "leftover children". The so-called arbitrariness refers to where the "leftover children" are isolated, and where the responsibility of taking care of children is apportioned. For example, in the first case, the 17-year-old child with cerebral palsy is apportioned to the village committee, in the fifth case, the responsibility of taking care of children is apportioned to the isolation point set by the health committee and tourism bureau. In other cases, the hospitals treating NCP patients are responsible to look after the children. The responsible institution is not unified obviously showing the characteristics of randomness. It also reflects that there is no "temporary guardianship" system to care for such "leftover children" in China. The so-called unprofessionality is that all kinds of individuals or institutions 
who take the initiative or passively take care of the "leftover children" have no common sense and experience of caring for children. Even in the case that hospitals is responsible to take care of these children, doctors and nurses who work in the department ofrespiratory related diseases take the burden, rather than paediatricians, therefore, they are not professional. The so-called regionality refers to the fact that in places out of Hubei province with relatively less severe epidemic situation, most isolated children can be taken care of, as the number of suspected and confirmed NCP infected patients is relatively small, and the total number of isolated children is relatively small. However, in Hubei province, due to the shortage of medical resources and insufficient beds, there are many NCP infected patients who cannot be admitted to the hospital. These infected people have to be isolated at home, which leads to cross infection among family members. When the life safety of these adults cannot be guaranteed, children's care and even survival problems shall get really tricky, for example, case 1 and case 8 mentioned above.

A significant problem presented by these cases is that the state has not taken the responsibility of "temporary guardianship" of "leftover children". Since the anti epidemic war has started, how to protect the most vulnerable group in this campaign, children, should be given enough attention.

In the civil law of guardianship system in China, it is clear that the guardianship system is based on family guardianship, supplemented by social guardianship and supported by state guardianship. Therefore, the state guardianship shall play an effective role when family guardianship of the above-mentioned "leftover children" is absent and social guardianship cannot be achieved. At present, the biggest problem is the absence of national guardianship.

\subsection{The Guardian's Awareness of Protecting Children's Rights Is Insufficient}

In addition to the absence of national guardianship, many guardians themselves have insufficient understanding of the protection of children's rights. For example, in the third and sixth cases listed above, parents left their 7-year-old and 8 -year-old sons at home alone. These parents thought that children who are 7 or 8 years old can take care of themselves, and teach their children how to live independently. They are not aware of the possible accidents may occur, they are not doing their best to find close relatives to help temporarily take care of children, and they do not ask for help from the state and society, hoping that relevant departments of the state or social caring people take care of their children.

The above phenomenon is closely related to the traditional concept of "parental rights" remaining in modern Chinese society. The traditional Chinese "parental rights" are different from the western countries' parental rights system based on the equality of personality. The traditional Chinese "parental rights" permeate the characteristics of patriarchal clan system and family ethics, and communicate with the concepts of "filial piety" and "loyalty". Therefore, the traditional Chinese "parental rights" are closely related to "imperial power" and "royal power". [8] Even though modern China abolished the traditional "parental rights" and established the guardianship system by imitating the Western parental rights system, in the social practice of China, the traditional parental rights, paternalism and the concept of parents are still far-reaching. This is reflected in the fact that many parents still take it for granted that they can completely control the freedom of children without violation of outside world. It is also reflected in the fact that many parents are unable to accept people out of their family circle to discipline their children, such as teachers' discipline of children, which is often the case of disputes between schools and parents. Naturally, they shall not agree that the state regulates their children's behaviors. Based on such tradition, China has not established a systematic planning for state custody, and our country still legislates the family marriage relationship based on the principle of not interfering too much in the internal family relationship. This traditional concept of parental rights leads to the situation that everyone only take care of their own safety, and parents are not be aware of seeking the protection for their children from the state.

\subsection{The Guidance of Public Opinion Is Unfavorable to the Protection of Children's Rights}

In fact, our whole society is also affected by this traditional concept of parental rights. We pay no attention to all kinds of children who are out of custody in the current epidemic, and appreciate the children who can live independently and reassure their parents. For example, China News Service reported on February 4, 2020,"Parents of police and doctors fight on the front line for NCP epidemic prevention and control, and their 7-year-old son living on instant noodles everyday". It was reported that $\mathrm{Mr}$. Wu, a police officer of the terminal of the Airport Public Security Bureau of Henan Provincial Public Security Department and his wife working in the Henan general hospital of Armed Police, joined in the epidemic prevention and control work at the first time after receiving the task, leaving their 7 years old son stayed at home alone. "This lovely and sensible child eats fancy instant noodles every day to reassure the parents on the front line." [6]

Qu Enze, a 10-year-old boy from Jiaozuo, Henan Province, whose father is a policeman and mother is a nurse, left a 10 -year-old at home after fighting the epidemic, the people's daily Weibo reported on February 1,2020. The boy did his homework, took Internet lessons, put on his mask and goggles to go shopping. For this, Simao education wrote a special article entitled "parents fight the front line of the epidemic, 10-year-old son takes care of himself alone, and the highest level of family education is willing to use children". [9] For such public opinion, lawyer Tong Lihua, a famous child rights protection expert, said that "such a thing is not worthy of public praise. The spirit of parents fighting in the front line of the Anti epidemic war is worthy of respect, but the situation of leaving children at home alone should not occur", and she called on the state and society to pay attention to the "leftover children" during the epidemic period. Children can not be unattended, otherwise, what's the meaning of rethinking fatal accidents occur? "[10] 


\section{Suggestions on the Protection of Children's Rights During the Epidemic}

According to Article 40 of the Law of the People's Republic of China on the Protection of Minors, priority shall be given to the rescue of minors in case of emergencies in schools, kindergartens, nurseries and public places. In response to the current social crisis, child protection should be given priority.

The first thing we must do is establishing a systematic national guardianship system, and clarified the temporary guardianship system. The original leftover children protection system in China can be used. On February 4, 2016, the State Council issued the opinions on strengthening the care and protection of leftover children in rural areas, requiring township governments and street offices to establish a detailed and complete information account of leftover children in rural areas. Every children has their own file, and the government shall implement dynamic management and precise measures. In May 2019, the Ministry of Civil Affairs, the Ministry of Education and other 10 departments jointly issued the opinions on further improving the care and service system for leftover children and children in difficulties, requiring the establishment of "children director" and "children supervisor", specifically responsible for the care and service work for leftover children and children in difficulties in rural areas. According to statistics, China has 45000 "child supervisors" and 620000 "child directors", and implements the real name management. [11] At present, the Ministry of Civil Affairs has taken action to guide local "child supervisors" and "child directors" to find children temporarily out of custody due to NCP epidemic under the unified deployment of township (street) and village (residential) committees. [12] The drawback is that these "children directors" and "children supervisors" are part-time workers. In the special period of epidemic prevention and control, how to make them play an effective role is still a problem. In order to solve this problem, it is necessary for the state to clearly designate the responsible organ according to the national guardianship responsibility, implement the protection tasks to specific departments and responsible persons, define the protection locations and measures, and improve the supervision and restriction mechanism. At present, civil affairs departments, which are in charge of taking in orphans and taking care of children, have not played any role in epidemic prevention and control.

Second, expanding the interpretation of leftover children and children in difficulties in the existing laws and policies, and formulating special provisions to protect children who are left alone because of the epidemic prevention. For example, Fang Yan, deputy to the National People's Congress and vice president of Shaanxi Lawyers Association, recently submitted the proposal on the protection of vulnerable groups of minors during the NCP epidemic to the Standing Committee of the National People's Congress. In view of the prevention and control of the epidemic situation of "temporary leftover minors", she promoted the revision of the regulations on Emergency Response to Public Health Emergencies and
National Emergency Response Plan for Public Health Emergencies as soon as possible, adding special provisions for the protection of "temporary leftover minors" during the epidemic prevention and control period, and designating special supervision organs to supervise the settlement of follow-up problems. [10] Build a well-known, fast and efficient rescue channel is necessary, such as clarifying responsible organs, or civil affairs departments take measures to inspire the enthusiasm of "children's directors" and "children's supervisors" throughout the country, and cooperate with communities or villages to carry out home observation, temperature detection, etc.

Finally, for the "leftover children" who are temporarily out of custody in epidemic areas, the state needs to allocate special funds to designate special national treatment institutions where children can recieve unified treatment. Yinchuan municipal government designated $\mathrm{MCH}$ to treat children suspected of NCP infection in the fourth case is a good example. Similar solutions can be popularized in various epidemic areas.

\section{Conclusion}

During the epidemic period, the protection of these children temporarily out of custody needs China to take the responsibility of national guardianship. Although some of these children get help from caring people, it is not enough. Many children are suffering from physical and mental torture in the unprecedented isolation. The responsibility of national guardianship can not only be solved by laws and regulations. It is not enough to inspire the enthusiasm of "children directors" and "children supervisors", and cooperate with communities or villages to carry out home observation, temperature detection and other measures, as these "children directors" and "children supervisors" are only part-time workers. They have no salary and only rely on appeal for mobilization. It is questionable how much help they can provide in practice. Therefore, the functional departments with real power must take the responsibility of looking after these special leftover children, which means the civil affairs department shall put out practical solutions, rather than only mobilizes some part-time workers to do some ineffective work.

\section{References}

[1] Zhang Yuemeng. A single parent suspected NCP was isolated in Hubei: a 17 year old cerebral palsy died 6 days after being alone at home. Beijing Youth Daily, 30 January, 2020.

[2] Zhang Duan. Parents were quarantined: their 8 months old baby was out of custody, and a male nurse born after 1995 became a temporary father. Beijing Youth Daily, 7 February, 2020 .

[3] Li Yifeng. 2020. A 8-year-old boy swipes his parents' credit card while their parents are isolated and spends 13000 yuan playing mobile games. Kankan news, 7 February, 2020. 
[4] Gao Wenwen and Jin Tao. 2020. A pair of parents in Yinchuan were diagnosed with NCP isolation, their three children were out of custody, and the "temporary mother" warmed their hearts. Yinchuan Daily, 6 February, 2020.

[5] Wu Di. 2020. Mother was diagnosed with NCP, a 9-year-old boy was isolated in a hotel was very anxious: his father was far away from the front line of anti epidemic in Wuhan. The People's daily, 5 February, 2020.

[6] Li Guigang. Parents of police and doctors fight at the front line of epidemic prevention and control, their 7-year-old son living on "fancy" instant noodles everyday. China News Service, 4 February, 2020

[7] Qi Wang. A 6-year-old girl exposes isolation at home alone. The Beijing News, 6 February, 2020.

[8] Yu Peifeng. Research on "parental rights": parental rights in the perspective of Chinese and western legal culture, China University of political science and Law Press, 2013 edition, P5.

[9] Zhang Xiaobai. Parents fight the front line of the epidemic: a 10 -year-old son takes care of himself alone. Tengxun news, 9 February, 2020.

[10] Xie Wenying. Prevention and control of epidemic situation: we should pay attention to leftover children. The Procuratorial Daily, 4 February, 2020.

[11] Jin Lijun. Legal topics in epidemic prevention and control. The Procuratorial Daily, 20 February, 2020.
[12] Ren Huan. Ministry of Civil Affairs: Strengthening the relief and guarantee work for children out of custody due to the impact of the epidemic. Guangming Daily, 12 February, 2020.

\section{Biography}

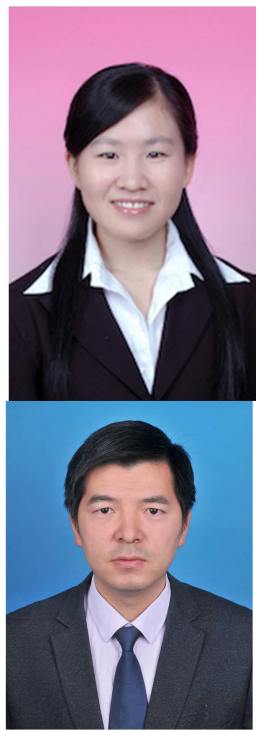

Xinlin Peng is a legal researcher and $\mathrm{PhD}$ supervisor at Law School of Beijing Normal University, and Deputy Secretary-General of China Criminal law Society. His research interests include Criminal law and Protection of the rights of minors.

Qian Sun is an assistant professor at Faculty of Humanities and Social Sciences, Beijing Institute of Education, Her research interests include law and Child Welfare. 